\title{
US widens the options on fusion research
}

David Dickson reports from Washington on new doubts about the future of the Tokamak

CONCERN at the potential engineering problems facing the development of nuclear fusion reactors based on the tokamak design is leading the US to widen the range of its search for potential fusion technologies.

Although the tokamak design is at present the closest to demonstrating its scientific feasibility-the design is also the basis of the Joint European Torus (JET) to be built by the EEC at Culham in the UK-scientists also fear that its engineering problems may prove to be the most complex.

\section{Magnetic mirrors}

In order to hold other options open, the US Department of Energy is contemplating holding back plans for further rapid expansion of the tokamak programme, and at the same time increasing the support that it provides for alternative fusions design concepts, in particular the use of magnetic mirrors for confining the superheated plasma.

The department is also reviewing a range of more speculative proposals, each of which is presently at little more than the theoretical stage, with a view to selecting two or three for increased funding. This would bring the work to a stage at which the potential commercial viability could be assessed against the more conventional approaches.

Ironically, one of the strong contenders for additional support is a magnetic confinement scheme being developed as the Los Alamos scientific laboratory using a method known as the 'reverse field pinch'. A configuration first noted-but at the time not properly understood-by British scientists using the UK Atomic Energy Authority's ZETA reactor at Harwell in the 1950s.

As fusion power rapidly approaches the first demonstrations of its scientific feasibility - Princeton University's Tokamak Fusion Test Reactor is due to begin operation in 1981, with intertial confinement at Los Alamos not far behind-congressional enthusiasm for promises of a clean, renewable source of energy is currently running high.

Last week, for example, the House of Representatives added \$22.9 million to the Department of Energy's request for fusion research in 1980, bringing the total to almost $\$ 225$ million. Of this figure, $\$ 8$ million is to establish a civilian research programme into the potential commercial exploitation of intertial confinement systems. At present all such work is being carried out in a military context because of the laser's capacity for triggering nuclear weapons.

The house also added $\$ 7$ million to fund studies of a highfield, scaled-down version of the tokamak, an idea being pushed by a firm called Inesco which, it is claimed, promises to provide commercial fusion power 10 to 15 years sooner than current fusion plans.

But if congressional representatives, many of whom reflect the growing interest in fusion technology of high technology companies such as the Grumman Corporation, are keen to press ahead quickly to the commercialisation stage, the administration is pausing to take a look at its priorities, attempting to make sure that the choices lying ahead are taken correctly.

\section{Critical reports}

Two recent reports have reflected this thinking. The first is a report prepared for the Office of Science and Technology Policy on basic research in the Department of Energy, which criticised attempts in both the magnetic confinement and intertial confinement fusion programmes to "move ahead too rapidly without adequate theoretical, experimental and engineering assessment of existing results".

The second is a more detailed report on fusion research prepared by a group chaired by Dr John S. Foster, VicePresident for Research and Development at TRW Inc., at the request of Dr John Deutch, Director of the Office of Energy Research in the Department.

This report expresses particular con- cern about the present heavy concentration of funds on experiments using tokamaks. The group claims that this strategy "places undue emphasis on a single approach, which constitutes an unnecessarily high risk" and suggests increased efforts in other areas to "allow a realistic choice to be made from among several hopefully viable alternatives".

The group says that although tokamaks are currently the most advanced scientifically, they seem on the surface to be the most complex of the possible alternative approaches to fusion from the standpoint of converting into an energy producer. It suggests that the present profusion of tokamaks is probably the result of a "bandwagon effect".

As to the intertial confinement technique, the report says that although here again demonstration of scientific feasibility is close, the programme so far has lacked adequate emphasis on the development of driver mechanisms capable of providing the system energy efficiency (the ratio of the energy in to the energy out) necessary for practical energy source.

Appearing just at the time when premliminary budget proposals for 1980 are being prepared for submission by government agencies to the Office of Management and Budget, these two reports have provided legitimation for the re-ordering of priorities for fusion research within the Department of Energy.

At one point, indeed, one of a range of proposals under consideration was to cut back severely funds for the magnetic fusion programme, diverting the funds to more long-range projects. Fol-

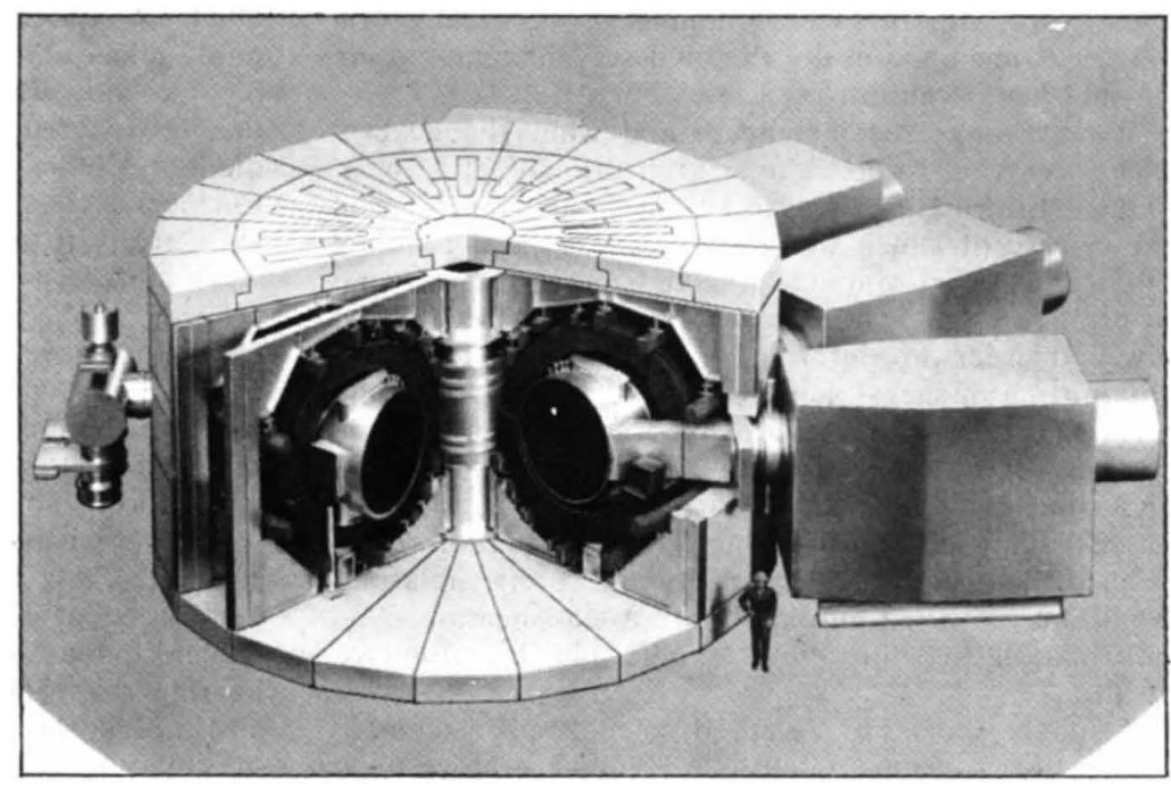

Princeton's Tokamak Fusion Test Reactor is due to go into operation in 1981. 
lowing sharp protests from Congress and elsewhere, however, this option has been discarded, and it looks as if funding for the magnetic fusion programme, although not as high as some would like to see, will be maintained at a reasonable level, although with a slight shift in emphasis from the tokamak projects to those involving mirror confinement.

At the same time the department is looking closely at other, less conventional schemes. Currently about 12 of these are being funded by the department-out of the 100 or so proposals which are received each year-at an annual cost of about $\$ 15$ million.

These various schemes are now being evaluated both from the scientific and the technological points of view, with the intention of selecting the two or three most promising to receive significant additional funding.

\section{More or fewer problems?}

At present, these various alternatives are so far behind the more main-line schemes that some are sceptical whether they can, in fact, ever catch up sufficiently to compete realistically. Others, however, feel that such additional funding could provide a breakthrough to a new system presenting fewer problems than those now being considered.

"We want to broaden the programme and develop alternatives to tokamak. I don't think anybody can say which approach will work the best, Dr Deutch said last week. "It's a matter of keeping the door open to new ideas," said another department official.

One result of holding back from putting all the research eggs into one basket-the lessons of which the administration has learnt from its experiences with the Clinch River Fast breeder--is that it could lengthen the timescale for the commercialisation of fusion energy. Dr Deutch is now predicting that the first commercial fusion reactor will be in operation by 2005 , and the second ten years after that.

In Europe, energy officials have been taking careful note of the two US reports. But, if it were necessary. it would not be an easy matter to shift the EEC five-year research programmes, which run from 1975-80. Mirror machines, of which there were many a decade ago in Europe, have been abandoned, and the commitment to JET is substantial.

The commissioner responsible for JET. M. Reginald Saison, said this week that "we are reassessing the technological problems". But he could not say if research funds would be shifted towards engineering and away from pure confinement research. "The matter is under discussion".

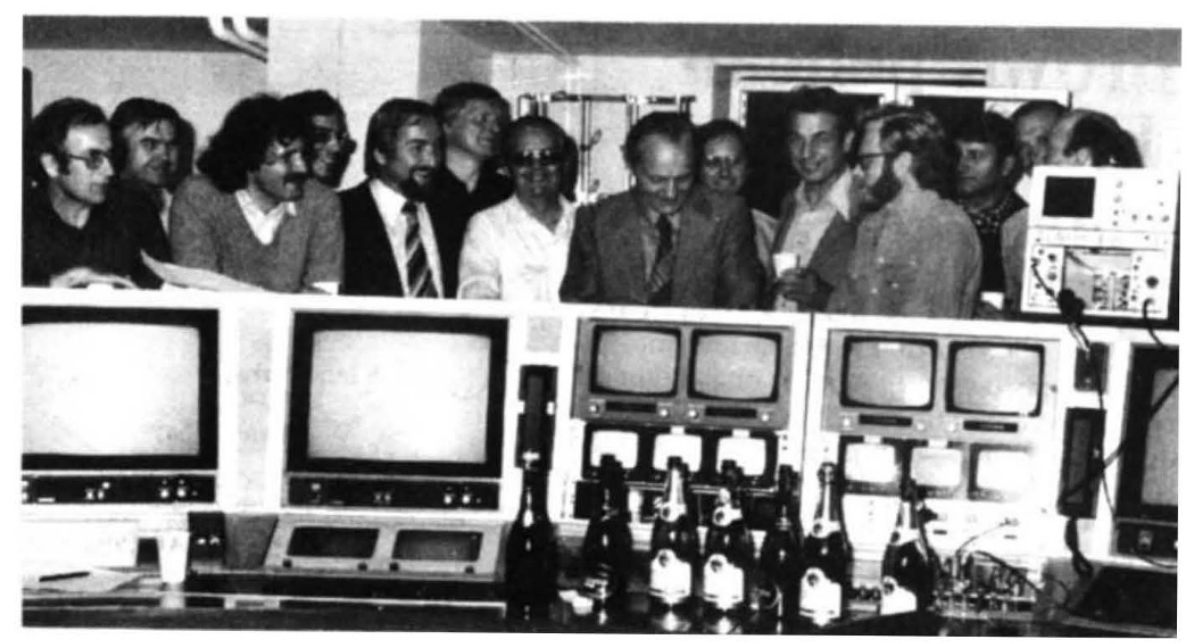

PETRA'S FIRST LIGHT: the first synchrotron light from PETRA, Germany's brand new accelerator, causes the physicists to celebrate. Centre, Professor Gustav-Adolf Voss, leader of the project. PETRA has aiready stored a 3 milliamp, $5 \mathrm{GeV}$ electron beam for 2 hours, and accelerated the beam from 5 to $8 \mathrm{GeV}$. This week it should accept positrons in the opposite direction and produce its first collisions. Commissioning is going "extremely well" says Voss, with the machine behaving almost exactly as predicted.

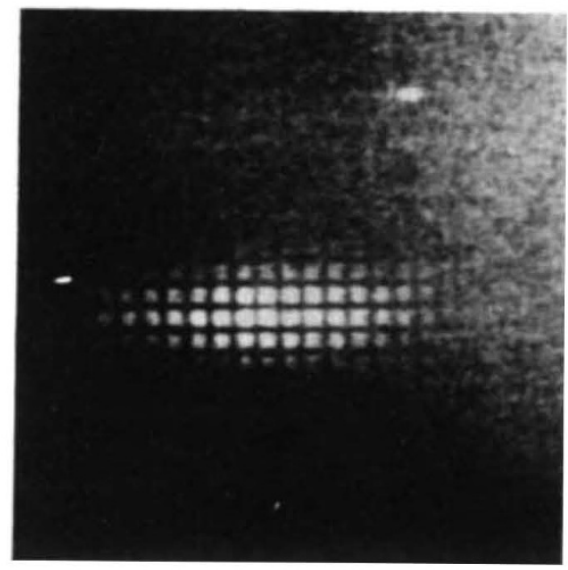

\section{NIH relaxes recombinant DNA guidelines}

A revised version of the guidelines for conducting research involving recombinant DNA techniques, in which the safety precautions required for a range of experiments would be substantially reduced, was due to be published this week by the US Department of Health, Education and Welfare.

The guidelines have been prepared by $\mathrm{Dr}$ Donald Fredrickson, director of the National Institutes of Health, following extensive discussion in both the scientific and the lay community, and taking into account the knowledge that has been gained about the use of the techniques since the existing guidelines were first published in June 1976

In the light of this new knowledge, the revised guidelines are expected both to relax the safety requirements for certain types of experiments, and exempt others from the need for regulation.

It is also expected that the new draft will compromise on an earlier suggestion that local biohazard committees be set up with the power to give the go-ahead to recombinant DNA experiments performed within the guidelines, merely supplying $\mathrm{NIH}$ with formal notification.

Following concern that such a system could lead to variations in interpretation of the guidelines, it is now expected that NIH approval will, as at present, still be required before new projects can go ahead, but that the local committees will be able to renew approval for such projects.

The draft version of the revised guidelines will be open for public discussion for a period of 60 days, after which a final version will be prepared and promulgated by Dr Fredrickson. $\mathrm{Mr}$ Joseph Califano, secretary of HEW, says in a preamble to the guidelines that he is particularly keen to receive comments on their nontechnical aspects, and a public hearing is to take place towards the end of the comment period, i.e. in mid-September.

Meanwhile in the House of Representatives, a bill sponsored by Representatives Harley Staggers and Paul Rogers to extend the NIH guidelines to cover all experiments involving recombinant DNA in both the public and private sector, of which little has been heard since March, is now expected to be debated on the floor of the House within the next few weeks.

But in the possible absence of any legislation, NIH is contemplating offering both a registration and a hostvector certification service to private companies as the basis of a system of voluntary compliance.

David Dickson 